\title{
PRIMER REGISTRO DE PALICUS ALTERNATUS RATHBUN, 1897 (DECAPODA: BRACHYURA), PARA CUBA
}

\author{
Carlos Varela \\ Department of Marine Biology and Fisheries, Rosenstiel School of Marine and Atmospheric Science, \\ University of Miami. varela06@gmail.com
}

\section{RESUMEN}

Se registra por primera vez para el archipiélago cubano Palicus alternatus Rathbun, 1897. Esta es la octava especie del género Palicus Philippi, 1838 registrada para Cuba.

Palabras clave: Decapoda, Brachyura, Palicus alternatus, primer registro, Cuba.

Title: First record of Palicus alternatus Rathbun, 1897 (Decapoda, Brachyura) for Cuba.

\section{ABSTRACT}

Palicus alternatus Rathbun, 1897, is recorded for the first time for Cuban archipelago. This is the eighth species recorded to Cuba of the genus Palicus Philippi, 1838.

Key words: Decapoda, Brachyura, Palicus alternatus, first record, Cuba.

Los representantes de la familia Palicidae se encuentran distribuidos principalmente a través en los océanos Pacífico e Índico con 11 géneros y más de 30 especies, mientras que para el Golfo de México y Mar Caribe hasta el momento solo se han registrado 12 especies pertenecientes al género Palicus Philippi, 1838 (Bermúdez et al., 2005; Felder et al., 2009). Aunque estos decápodos, son en su mayoría habitantes de aguas profundas, por lo que el conocimiento acerca de su biología es muy limitado, existen especies que pueden habitar en aguas más someras (Hernando Campos y Werding, 1991 y Bermúdez et al., 2005). Para Cuba se han registrado hasta el momento 7 especies de estos crustáceos (Lalana y Ortiz, 2000), las cuales en su mayoría fueron colectados durante los bojeos de estudio realizados por el buque "Atlantis" en los años 1938 y 1939 (Chace, 1940).

El ejemplar estudiado fue encontrado en el contenido estomacal de Pterois volitans (Linnaeus, 1758). El pez fue capturado con jamos con el auxilio de SCUBA en el sublitoral frente al Acuario Nacional de Cuba. El sistema de clasificación empleado fue el de $\mathrm{Ng}$ et al., (2008).

Familia Palicidae Bouvier, 1898

Género Palicus Philippi, 1838

Palicus alternatus Rathbun, 1897

Material estudiado. Una hembra. Hallada en contenido estomacal de Perois volitans en el sublitoral frente al Acuario Nacional de Cuba $\left(23^{\circ} 07^{\prime} 03\right.$ " $\mathrm{N}$ y 82 $\left.26^{\circ} 16^{\prime \prime} \mathrm{W}\right)$, a $27 \mathrm{~m}$ de profundidad, provincia de La Habana el 23 de mayo del 2011. 
Comentario. Esta especie se diferencia de las restantes del género en que su segundo par de pereiópodos no es más de dos veces el ancho del carapacho y el último segmento esternal no presenta crestas laminares conspicuas en vista dorsal.

Esta especie ha sido citada en varias localidades desde Cabo Hatteras (U. S. A.), el Golfo de México y Brasil (Hernando Campos y Werding, 1991).

\section{AGRADECIMIENTOS}

Al colega y amigo Pedro Chevalier (Acuario Nacional de Cuba) por la ayuda en la colecta de los ejemplares de Pterois sp. Este trabajo se efectuó en el marco del proyecto "Estudio preliminar de las poblaciones invasoras del pez léon (Teleostei: Scorpaeniadae: Pterois sp.) en aguas cubanas."

\section{LITERATURA CITADA}

Bermúdez, A., N. Cruz, G. Navas y N. Hernando Campos. 2005. Nuevos registros de cangrejos del género Palicus (Philippi, 1838) (Crustacea: Decapoda: Brachyura: Palicidae) para el Mar Caribe colombiano. Boletín de Investigaciones Marinas y Costeras 34: 81-100.

Chace, F. A., Jr. 1940. Reports on the scientific results of the Atlantis expedition to the West Indies, under the joint auspices of the University of Havana and Harvard University. Torreia 4: 3-67.

Felder, D. L., F. Álvarez, J. W. Goy y R . Lemaitre. 2009. 59 . Decapoda (Crustacea) of the Gulf of Mexico, with comments on the Amphionidacea. In: Gulf of Mexico, origins, water and biota (John W. Tunnell, Darryl L. Felder and Sylvia A. Earle eds.), 1104-1019.

Hernando Campos, N. y B. Werding. 1991. Palicus alternatus Rathbun (Decapoda: Brachyura) un nuevo registro para el Caribe colombiano. Caldasia 16 (78): 349-354.

Lalana, R. y M. Ortiz. 2000. Lista actualizada de los crustáceos decápodos de Cuba. Revista de Investigaciones Marinas. 21 (1-3): 33-44.

Ng. P. K. L., D. Guinot y P. J. F. Davie. 2008. Systema Brachyurorum: Part I. An annotated checklist of extant brachyuran crabs of the world. The Raffles Bulletin of Zoology, supplement 17: 1-286.

[Recibido: 02 de octubre del 2012. Aceptado para publicación: 01 de febrero del 2013] 